\title{
New Distributional Records of Three Species of Euphylliidae (Cnidaria, Anthozoa, Hexacorallia, Scleractinia) from the Ryukyu Islands, Japan
}

\author{
Takuma Fujii ${ }^{1,4}$, Yuko F Kitano ${ }^{2}$, and Hiroyuki Tachikawa ${ }^{3}$ \\ ${ }^{1}$ International Center for Island Studies Amami Station, Kagoshima University, \\ 15-1-6F Naze-Minatomachi, Amami, Kagoshima 894-0026, Japan \\ E-mail:tfujii@cpi.kagoshima-u.ac.jp \\ ${ }^{2}$ National Institute for Environmental Studies, 16-2 Onogawa, Tsukuba, Ibaraki 305-8506, Japan \\ ${ }^{3}$ Coastal Branch of Natural History Museum and Institute, Chiba, 123 Yoshio, Katsuura, Chiba 299-5242, Japan \\ ${ }^{4}$ Corresponding author
}

(Received 6 December 2019; Accepted 11 March 2020)

\begin{abstract}
Three species of the family Euphylliidae (Cnidaria, Anthozoa, Hexacorallia, Scleractinia) have been formally recorded for the first time from the Ryukyu Islands, Japan, based on specimens. Their unique polyp morphology, such as the combination of extended tentacle, are considered to be useful for taxonomy at the species level in genus Fimbriaphyllia Veron and Pichon, 1980 and Euphyllia Dana, 1846. One reason that their distribution might have been overlooked is the insufficiency of environmental surveys, including turbid, sheltered, and upper mesophotic environments.
\end{abstract}

Key Words: Anthozoa, Scleractinia, Euphylliidae, Ryukyu Islands, Fimbriaphyllia, Catalaphyllia.

\section{Introduction}

The family Euphylliidae (Cnidaria, Anthozoa, Hexacorallia, Scleractinia) currently consists of eight genera (Luzon et al. 2018). Specimens of most of its species expand their fleshy soft body to protrude from the corallites when they are alive. In contrast to their unique polyp morphology, the skeletal features of the species within this family are not sufficiently varied to utilize for their taxonomy. Recently, a reconstruction of the classification based on molecular phylogenetic studies has been performed, and they proposed the resurrection of the genus Fimbriaphyllia Veron and Pichon, 1980 (Luzon et al. 2018), the shift of the genus Galaxea Oken, 1815 into the family, and the removal of the genera Plerogyra Milne Edwards and Haime, 1848, Physogyra Quelch, 1884, and Nemenzophyllia Hodgson and Ross, 1982, which are now temporarily classified as family incertae sedis (Benzoni et al. 2014), respectively. However, a comprehensive understanding of their taxonomy has not yet been achieved. One of the obstacles is the difficulty in collection of some rare species.

Previously, three species of the genus Fimbriaphyllia, including F. ancora (Veron and Pichon, 1980), F. divisa (Veron and Pichon, 1980), and F. yaeyamaensis (Shirai, 1980), were known in Japan and found to be widely distributed in the Indian Ocean to the Western and Central Pacific, (e.g., Cairns 1999). In addition to the three known species, $F$. paraancora (Veron, 1990) and F. paradivisa (Veron, 1990) were mentioned or photographed as species with a possible distribution in Japan (Eyal et al. 2016; Miyakojima City Board of Education 2016; Yokochi et al. 2019), although there has not been a specimen-based record in Japan thus far. Catalaphyllia jardinei (Saville-Kent, 1893) is known as a widely distributed euphylliid species as well but has been designated as a vulnerable species by the Ministry of Environment in Japan as well as the IUCN Red List because of its rarity (Ministry of Environment, Japan 2017; International Union for Conservation of Nature 2019). Additionally, C. jardinei is considered to be distributed discontinuously in Japan, as it is known only in temperate regions and has not been formally reported based on the specimens or photographs in the subtropical regions of the Ryukyu Islands, although it is known in Southeast Asia (Nishihira and Veron 1995; Ministry of Environment, Japan 2017).

In this study, we formally report on three zooxanthellate species of the family Euphylliidae, i.e., F. paraancora, F. paradivisa, and C. jardinei, based on voucher specimens from the Ryukyu Islands, Japan.

\section{Materials and Methods}

The specimens were collected by hand or by using a hammer with a chisel by divers utilizing SCUBA after in situ photos were taken with digital cameras. The skeletal specimens were preserved by removing the tissues with bleach and drying. The measurement was performed using a vernier caliper with units of $0.1 \mathrm{~mm}$. The specimens were deposited in the Kagoshima University Museum (KAUM), Coastal Branch of Natural History Museum and Institute, Chiba (CMNH), and the Smithsonian National Museum of Natural History (USNM). 


\section{Results}

Family Euphylliidae Alloiteau, 1952

Genus Fimbriaphyllia Veron and Pichon, 1980
Fimbriaphyllia paraancora (Veron, 1990)

[New Japanese name: Tsutsu-nagarehana-sango]

(Figs 1A, D, 2A-D)

Euphyllia paraancora Veron, 1990: 159-162, figs 65-69, 90;

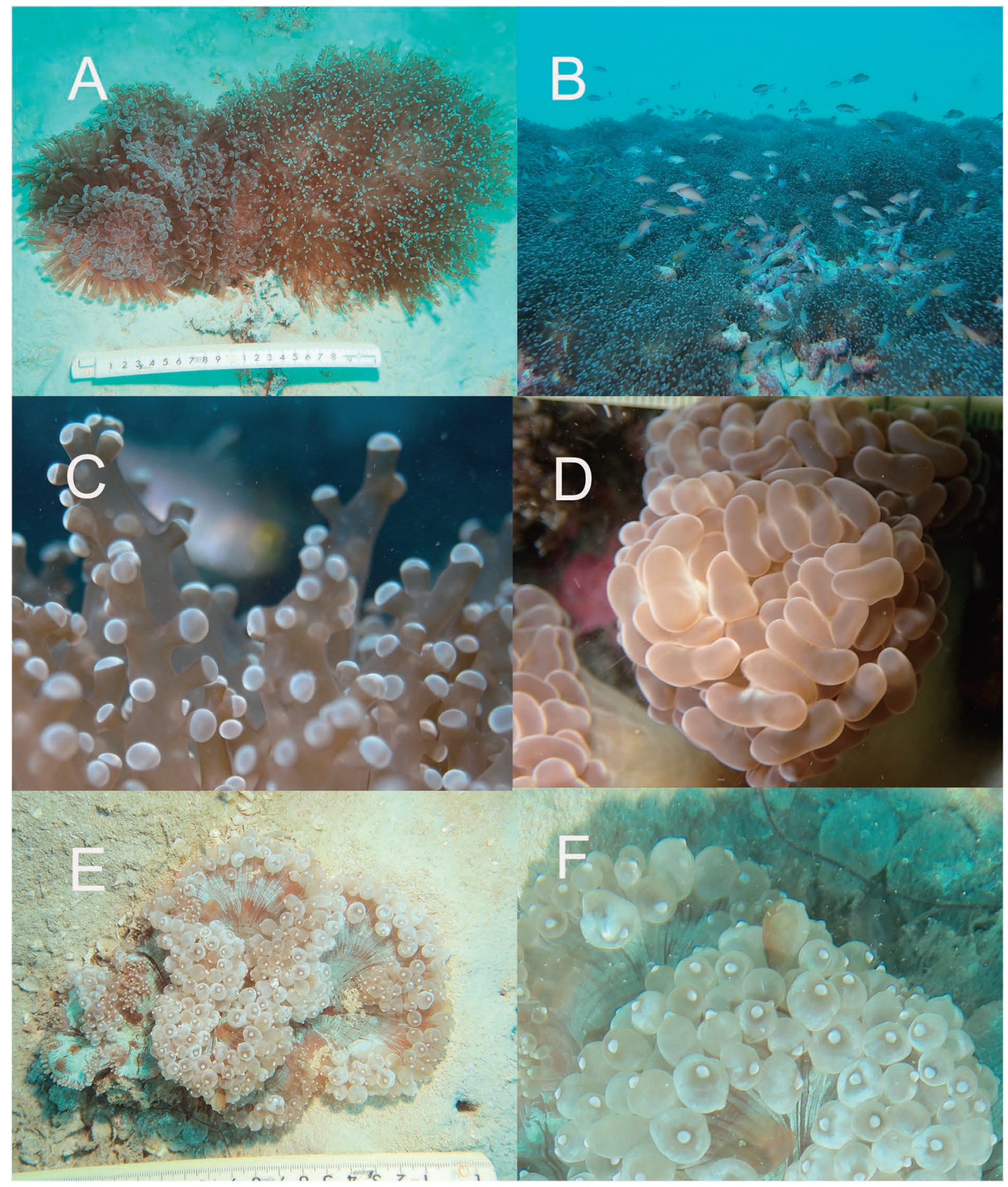

Fig. 1. Underwater appearance of living corals. A, in situ photograph of the colonies of Fimbriaphyllia paraancora (KAUM-CN-10) on the left and F. paradivisa (KAUM-CN-11) at Tean, Amami-Oshima island, Kagoshima, Japan, on 21 December 2017; B, an aggregation of F. paradivisa approximately $3-5 \mathrm{~m}$ in diameters on the muddy bottom in the usually turbid inner bay at a depth $28 \mathrm{~m}$, Henoko, Okinawajima island, Okinawa, Japan, on 25 November 2010; C, extended polyps of F. paradivisa showing branching tentacles with spherical ends; D, extended polyps of F. paraancora showing tentacles with anchor-shaped tips; E, in situ photograph of Catalaphyllia jardinei (KAUM-CN-14) at Tean, Amami-Oshima island, Kagoshima, Japan, on 21 December 2017; F, polyps of C. jardinei showing small bubble-shaped tentacles at the edge of the oral disc. 
Wolstenholme et al. 1997: 389, table 2; Kenyon et al. 2011: 3, table 3; Hsieh et al. 2001: 316-317; Hoeksema and Waheed 2012: 299, fig. 2; Turak et al. 2012: 53-58; Waheed et al. 2015a: fig. 8c; Luzon et al. 2018: 1-11.

Specimens examined. KAUM-CN-100, a corallum of $81 \mathrm{~mm}$ height from the base, with three corallites of 14.4-34.2 mm greater calicular diameter (GCD), Tean, Oshima Strait, Setouchi, Amami-Oshima island, Kagoshima, Japan $\left(28^{\circ} 9^{\prime} 38.98^{\prime \prime} \mathrm{N}, 129^{\circ} 17^{\prime} 35.04^{\prime \prime} \mathrm{E}\right), 32 \mathrm{~m}$ in depth, collected by Takuma Fujii on 21 December 2017; CMNHZG 09105, a corallum of $55 \mathrm{~mm}$ height, with seven corallites of 15.2-35.3 mm GCD, Tean, Oshima Strait, Setouchi, Amami-Oshima island, Kagoshima, Japan $\left(28^{\circ} 9^{\prime} 39.00^{\prime \prime} \mathrm{N}\right.$, $\left.129^{\circ} 17^{\prime} 35.00^{\prime \prime} \mathrm{E}\right), 35 \mathrm{~m}$ in depth, collected by Hiroyuki Tachikawa on 3 February 2018; CMNH-ZG 08523, a corallum of $154 \mathrm{~mm}$ height, with six corallites of $21.9-37.1 \mathrm{~mm}$ GCD, Wase, Sumiyo Bay, Amami, Amami-Oshima island, Kagoshima, Japan $\left(28^{\circ} 17^{\prime} 36.04^{\prime \prime} \mathrm{N}, 129^{\circ} 28^{\prime} 32.00^{\prime \prime} \mathrm{E}\right), 9 \mathrm{~m}$ in

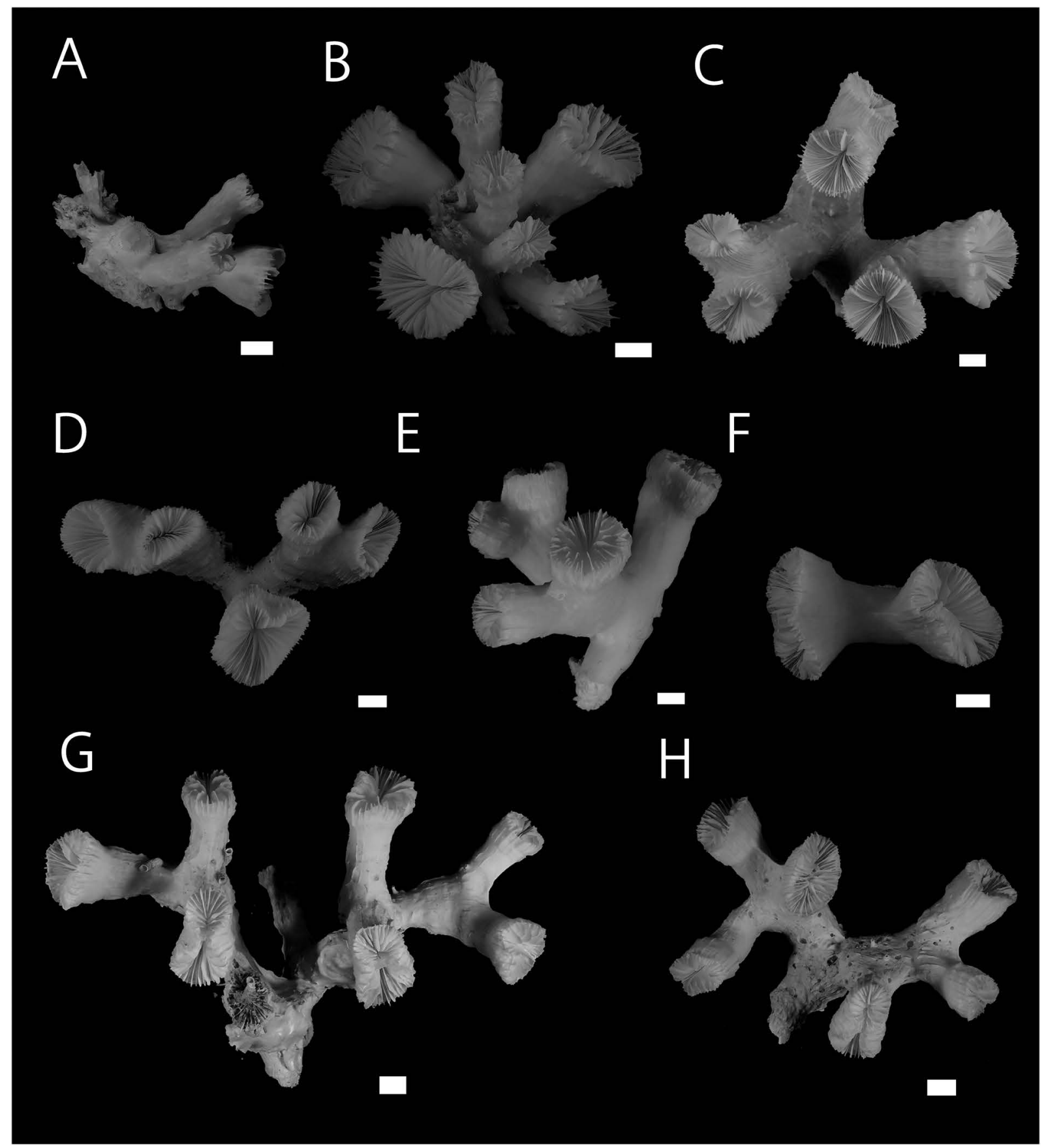

Fig. 2. Corallum of Fimbriaphyllia species currently reported from the Ryukyu Islands, Japan, F. paraancora (A-D) and F. paradivisa (E-H). A, KAUM-CN-10, Tean, Amami-Oshima island, Kagoshima, Japan, depth of 32 m; B, CMNH-ZG09105, Tean, Amami-Oshima island, Kagoshima, Japan, depth of 35 m; C, CMNH-ZG 08523, Wase, Amami-Oshima island, Kagoshima, Japan, depth of 9 m; D, CMNHZG 07195, Ii-nanshi, Ogamijima island, Okinawa, Japan, depth of 10 m; E, KAUM-CN-11, Tean, Amami-Oshima island, Kagoshima, Japan, depth of 32 m; F, CMNH-ZG 09661, Tean, Amami-Oshima island, Kagoshima, Japan, depth of 32 m; G, KAUM-CN-12, Henoko, Okinawajima island, Okinawa, Japan, depth of 28 m; H, CMNH-ZG-09661, Henoko, Okinawajima island, Japan, depth of $28 \mathrm{~m}$. 
depth, collected by Hiroyuki Tachikawa on 11 September 2017; and CMNH-ZG 07195, a corallum of $108 \mathrm{~mm}$ height from base, with five corallites of $23.1-35.0 \mathrm{~mm}$ GCD, Iinanshi, Miyakojima, Ogamijima island, Okinawa, Japan $\left(24^{\circ} 55^{\prime} 29.13^{\prime \prime} \mathrm{N}, 125^{\circ} 18^{\prime} 20.48^{\prime \prime} \mathrm{E}\right), 10 \mathrm{~m}$ in depth, collected by Hiroyuki Tachikawa on 7 July 2015.

Morphology. The morphological features of the soft body and the skeletal characteristics examined in this study agreed with the original description. Colony phaceloid with fleshy tentacles with anchor-shaped tips extend during day (Fig. 1A, D). Tubular corallum branching with weak costae, epitheca absent. Corallites greater diameter $14-37 \mathrm{~mm}$ in this study, up to four cycles of fine granulated septa without pali (Fig. 2A-D). Columella absent.

Habitat and distribution. Specimens collected in the current study were from hilly, muddy, and rubbly seafloor areas at depth greater than $30 \mathrm{~m}$ inside a bay (Tean) or on the undulating reef wall in comparatively turbid and sheltered coral reef areas at the mouth of a bay (Wase). This species was previously known from Bolinao (the Philippines) of the type locality, Motupore (Papua New Guinea) (Veron 1990), Penghu (Taiwan) (Hsieh et al. 2001), Kota Kinabalu (Malaysia) (Hoeksema and Waheed 2012), Spratly Islands (Waheed et al. 2015a), Bali (Indonesia) (Turak et al. 2012), Northern Australia (Wolstenholm et al. 1997), and Guam (Randall and Myers 1983; Randall 2003). A photograph in a field guide to coral in Japan representing the features of this species showed the possibility of its distribution in Japan (Nishihira and Veron 1995); however, no information about the photograph was available. Yokochi et al. (2019) listed this species from Iriomotejima island, Japan without any vouchers. The specimens in this study formally represent the northernmost distributional record and the first record from Japan.

Remarks. The soft body of F. paraancora resembles F. ancora in its anchor-shaped tentacles (Fig. 1D), but it was easy to distinguish through its colony shape, as the latter forms a flabello-meandroid corallum (Fig. 2A-D). It is difficult to distinguish from other phaceloid species in the family Euphylliidae, such as Euphyllia glabrescens (Chamisso and Eysenhardt, 1821), E. paraglabrescens Veron, 1990, and F. paradivisa by its skeletal features alone, with the exception of Euphyllia baliensis Turak, Devantier, and Erdman, 2012, which has a unique tetra or octermal septal pattern and small calicular diameter. This species can be distinguished from the other species in the same genus by genetic sequencing as well (Luzon et al. 2018).

Fimbriaphyllia paradivisa (Veron, 1990)

[New Japanese name: Tsutsu-koeda-nagarehana-sango] (Figs 1A-C, 2E-H)

Euphyllia paradivisa Veron, 1990: 157-159, figs 63, 64, 89; Kenyon et al. 2011: 3, table 3; Eyal et al. 2016: 91-100; Luzon et al. 2018: 1-11.

Fimbriaphyllia paradivisa: Montgomery et al. 2019: 54, 158.

Specimens examined. KAUM-CN-11, a corallum of $95.1 \mathrm{~mm}$ height from the base, with five corallites of 18.1-
$29.4 \mathrm{~mm}$ and a dividing corallite of $46.1 \mathrm{~mm}$ GCD, Tean, Oshima Strait, Setouchi, Amami-Oshima island, Kagoshima, Japan $\left(28^{\circ} 9^{\prime} 38.98^{\prime \prime} \mathrm{N}, 129^{\circ} 17^{\prime} 35.04^{\prime \prime} \mathrm{E}\right), 32 \mathrm{~m}$ in depth, collected by Takuma Fujii on 21 December 2017; CMNHZG 09104, a fragment of a corallum of $80 \mathrm{~mm}$ height, with two corallites of $38.6-41.1 \mathrm{~mm}$ GCD, $32 \mathrm{~m}$ in depth, the same site as KAUM-CN-11, originally a part of the colony of KAUM-11 and separated by Takuma Fujii on 21 December 2017 and collected by Hiroyuki Tachikawa on 3 February 2018; KAUM-CN-12, a corallum of $140 \mathrm{~mm}$ height, with five oval corallites of $19.5-27.2 \mathrm{~mm}$, two dividing corallites of 34.0-29.8, and a dead corallite of $30 \mathrm{~mm}$ GCD, Henoko, Oura Bay, Nago, Okinawajima island, Okinawa, Japan $\left(26^{\circ} 31^{\prime} 50.85^{\prime \prime} \mathrm{N}, 128^{\circ} 3^{\prime} 17.98^{\prime \prime} \mathrm{E}\right), 28 \mathrm{~m}$ in depth, collected by Masaru Mizuyama on 16 September 2018; and CMNH-ZG 09661, a corallum of $101 \mathrm{~mm}$ height from the base, with five corallites of $21.0-27.8 \mathrm{~mm}$ GCD with a dividing corallite of $33.4 \mathrm{~mm}$ GCD, Henoko, Oura Bay, Nago, Okinawajima island, Okinawa, Japan $\left(26^{\circ} 31^{\prime} 50.85^{\prime \prime} \mathrm{N}, 128^{\circ} 3^{\prime} 17.98^{\prime \prime} \mathrm{E}\right), 28 \mathrm{~m}$ in depth, collected by Masaru Mizuyama on 16 September 2018.

Morphology. The morphological features of both the soft body observed in situ and the skeletal characteristics examined in this study agree with the original description. Colony phaceloid, tentacles branching with spherical ends (Fig. $1 \mathrm{~A}-\mathrm{C})$. Tubular corallum branching with weak costae, epitheca absent. Corallites greater diameter $14-30 \mathrm{~mm}$ in this study, up to four cycles of fine granulated septa without pali. Columella absent (Fig. 2E-H).

Habitat and distribution. Specimens collected by the current study were from hilly, muddy, and rubbly seafloor areas of depth greater than $30 \mathrm{~m}$ inside two bays of Okinawajima island and Amami-Oshima island, respectively (Henoko and Tean). This species was described from a depth of $8 \mathrm{~m}$ in Bolinao, Philippines, by Veron (1990), and, at present, is known from Lian (Philippines; Luzon et al. 2018), American Samoa (USA) (Montgomery et al. 2019), and Eilat (Israel) (Eyal et al. 2016). In Japan, in situ photographs of the large assemblage of presumed members of this species were posted in a book (Diving Team Snuck Snufkin 2015); however, no specimen-based record has been made thus far. Additionally, specimens from Okinawajima island were suggested by Eyal et al. (2016), but they are in a private collection, and the information is unavailable. The present study formally represents the new and northernmost distributional record of F. paradivisa from Japan based on the available specimens.

Remarks. The soft body of $F$. paradivisa resembles that of F. divisa in its branching tentacles with spherical ends (Fig. $1 \mathrm{C})$, but it is easy to distinguish through its colony shape, as the latter forms a flabello-meandroid corallum (Fig. 2E-H). This species can also be distinguished from other species in the same genus by genetic sequencing (Luzon et al. 2018). Although this species was previously known only from a few locations, it is likely that immature colonies of F. paradivisa were confused with $F$. divisa and overlooked in some places. The species' habit of forming assemblage at greater depths, such as mesophotic zones, might have been overlooked as 
well, as suggested by Eyal et al. (2016).

Genus Catalaphyllia Wells, 1971

Catalaphyllia jardinei (Saville-Kent, 1893)

(Figs 1E, F, 3, 4)

Pectinia jardinei Savill-Kent, 1893: 158, pl. 4.

Catalaphyllia jardinei: Wells 1971: 368-370; Veron 2000: 82-

83; Nomura and Mezaki 2015: 35, pl. 2.

Euphyllia sabiuraensis Eguchi, 1973: 82-83, pl. 1.

Cattalophyllia sabiuraensis: Eguchi and Miyawaki 1975: 54,

pl. 6; Kushimoto Marine Park Center 1977: 3, 48.

Catalaphyllia sabiuraensis: Shirai 1977: 584.

Specimens examined. KAUM-CN-13, a fan-shaped corallum with a pointed base, corallum height of $126.4 \mathrm{~mm}$, elongated calice of $209.3 \times 26.8 \mathrm{~mm}$ calicular diameter, calice bifurcated and trifurcated at each end, Tean, Oshima Strait, Setouchi, Amami-Oshima island, Kagoshima, Japan $\left(28^{\circ} 9^{\prime} 38.98^{\prime \prime} \mathrm{N}, 129^{\circ} 17^{\prime} 35.04^{\prime \prime} \mathrm{E}\right), 32 \mathrm{~m}$ in depth, collected by Takuma Fujii on 20 December 2018; CMNH-ZG 09662, a fan-shaped corallum with a pointed base; corallum height of $78.1 \mathrm{~mm}$; elongated calice of $123.0 \times 34.2 \mathrm{~mm}$ calicular diameter, Tean, Oshima Strait, Setouchi, Amami-Oshima island, Kagoshima, Japan $\left(28^{\circ} 9^{\prime} 38.98^{\prime \prime} \mathrm{N}, 129^{\circ} 17^{\prime} 35.04^{\prime \prime} \mathrm{E}\right)$, $32 \mathrm{~m}$ in depth, collected by Takuma Fujii on 21 December 2017; and KAUM-CN-14, a fan-shaped corallum with a pointed base, $96.8 \mathrm{~mm}$ in height, elongated calice of $177.9 \times 33.6 \mathrm{~mm}$ calicular diameter, Nishikomi, Oshima Strait, Setouchi, Amami-Oshima island, Kagoshima, Japan $\left(28^{\circ} 14^{\prime} 28.86^{\prime \prime} \mathrm{N} 129^{\circ} 10^{\prime} 6.33^{\prime \prime} \mathrm{E}\right), 31 \mathrm{~m}$ in depth, collected by Takuma Fujii on 03 May 2019.

Comparative specimens examined. Photographs of the previously collected specimens are shown in Fig. 4. USNM 1259568, Horseshoe Cliffs, Onna, Okinawajima island, Okinawa, Japan, depth range $52-55 \mathrm{~m}$, collected by Robert $\mathrm{F}$ Bolland on 21 December 1988. USNM 94409, off Nago City, Nago, Okinawajima island, Okinawa, Japan, $27 \mathrm{~m}$ in depth, collected by Robert F. Bolland on 21 February 1992.

Morphology. The specimens collected at Amami-Oshima island show typical features of the current monotypic genus Catalaphyllia Wells, 1971, solid flabello-meandroid corallum with wide $\mathrm{V}$-shaped valley moderately and linearly became hollow into the center, septa with a few teeth developed only in the inner margin (Fig. 3). The living polyp also shows the unique feature of the genus in thick fleshy oral disc which is expanded during the day and tubular to small

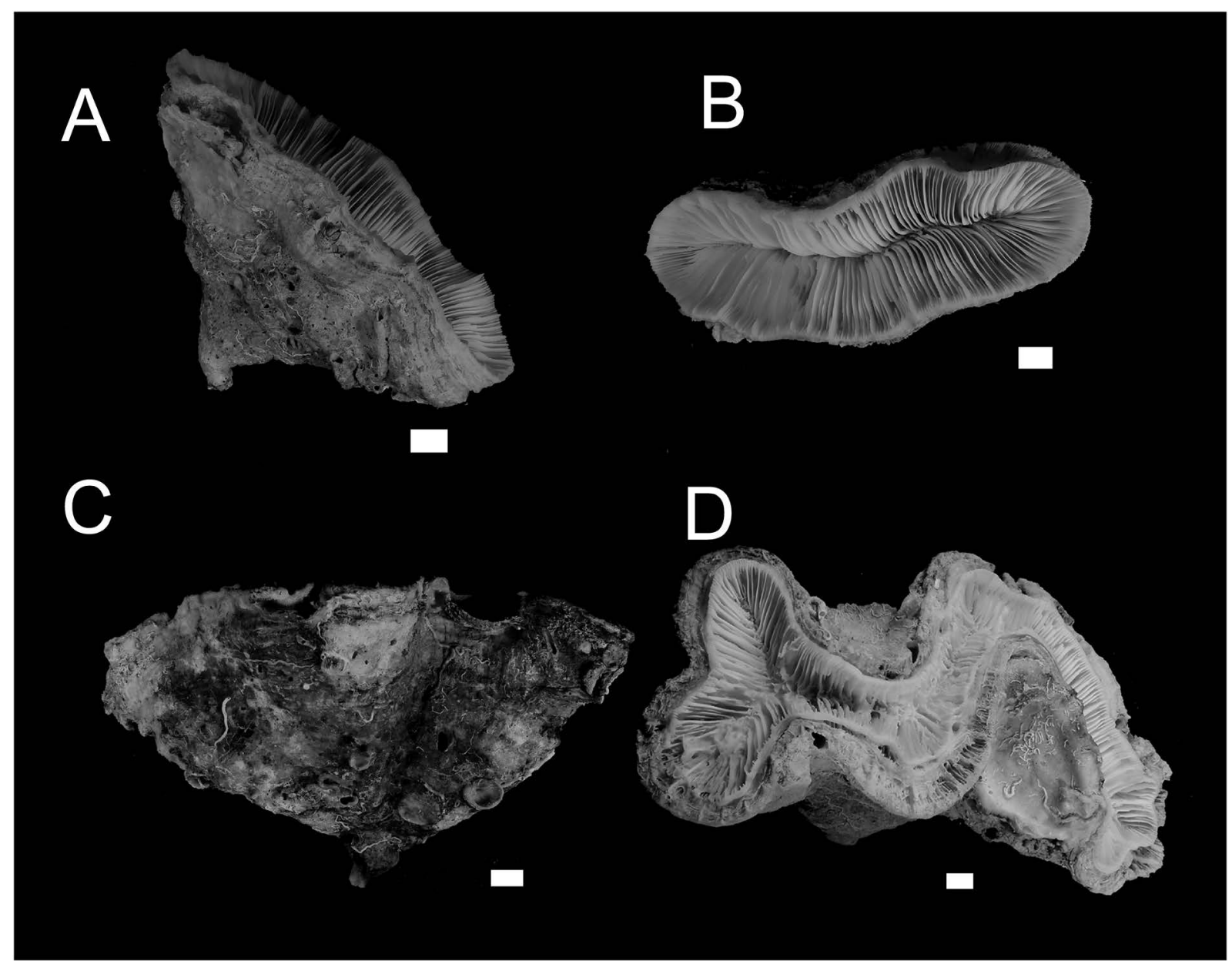

Fig. 3. Corallum of Catalaphyllia jardinei currently reported from Amami-Oshima island, Japan. A, side view of the corallite of KAUMCN-14; B, view from the top side of the corallite and the calice of KAUM-CN-14; C, side view of the corallite of CMNH-ZG 09662; D, view from the top side of the corallite and the calice of CMNH-ZG 0966 showing three-forked branching of the calice. 
bubble-shaped tentacles with a spherical tip at the edge (Fig. 1E, F).

Habitat and distribution. Specimens collected in the current study were from hilly, muddy, and rubbly seafloor areas at a depth greater than $30 \mathrm{~m}$ inside two different bays in the Oshima Strait (Tean and Nishikomi). Catalaphyllia jardinei was originally described from the Great Barrier Reef, Australia (Saville-Kent 1893), and is also known from the northern Great Barrier Reef (Veron and Pichon 1980), New Caledonia (Wells 1971), Malaysia (Waheed and Hoek- sema 2014) and Indonesia (Best et al. 1989). In Japan, this species has been reported only in temperate (northern) localities such as Miyazaki (Fukami pers. comm.; Ministry of Environment, Japan 2017), Kumamoto, Kagoshima, Nagasaki (Ministry of Environment, Japan 2017), Kochi (Nomura and Mezaki 2015), and Wakayama (e.g., Eguchi 1973; Nomura and Hirabayashi 2018). Although the Ryukyu Islands have been considered as a distributional gap in the species (e.g., Nishihira and Veron 1995; Veron 2000), two specimens from the east shore of Okinawajima island, in

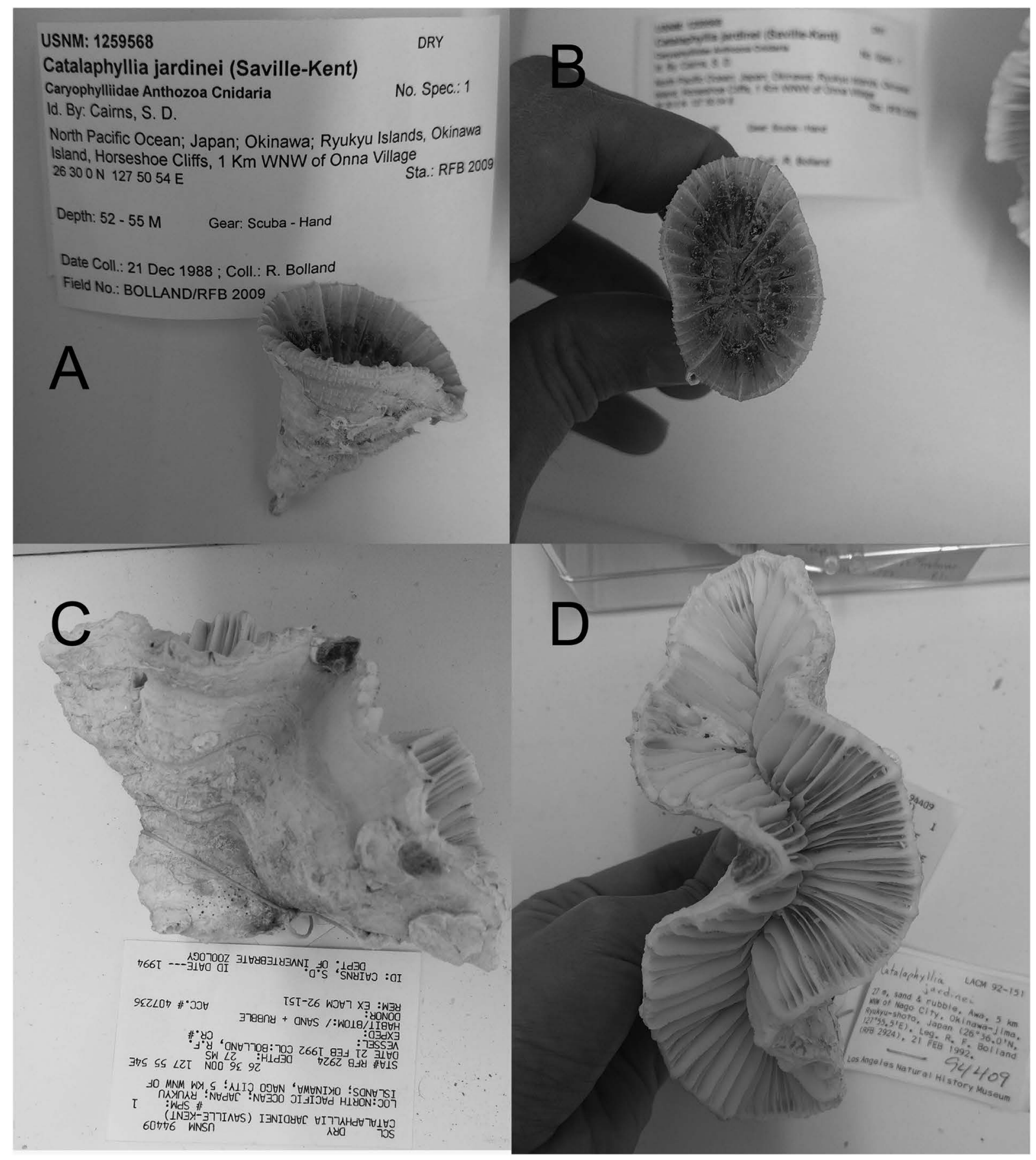

Fig. 4. Specimens of Catalaphyllia jardinei preserved in the Smithsonian National Museum of Natural History (Photographs taken by Allison Becker) (USNM). A-B, corallite of USNM 1259568, collected at 52-55 m deep off Manza Horshoe Cliffs, Onna, Okinawajima island, Okinawa, Japan, on 21 December 1988, by Robert F. Bolland; C-D, corallite of USNM 94409, collected at $27 \mathrm{~m}$ deep off Nago City, Nago, Okinawajima island, Okinawa, Japan, on 21 February 1992, by R. F. Bolland. 
the middle of the Ryukyu Islands, have been kept at USNM without publication (USNM 94409 and USNM 1259568; Fig. 4). Both specimens from Amami-Oshima island in the current study and the USNM specimens from Okinawajima island fill the distributional gaps of $C$. jardinei between the tropical Western Pacific region and temperate Japan. Sinniger et al. (2019) observed C. jardinei at mesophotic region of Sesokojima island, Okinawa.

Remarks. Two nominal species of Catalaphyllia, C. sabiuraensis Eguchi, 1973, and C. okinawaensis Eguchi and Shirai, 1977, have been described from Japan. At present, these two species are considered to be junior synonyms of $C$. jardinei and E. glabrescens, respectively (Veron 1992). Currently, the genus Catalaphyllia is considered to be monospecific, with its sole member being $C$. jardinei. Because of its rarity, not much information about the genus has been reported in Japan, and a taxonomical reexamination including its phylogenetic position is necessary.

\section{Discussion}

Amami-Oshima island, the second-biggest island in the Ryukyu Islands, is located close to the northernmost area with developed coral reef. In addition, it is known as the area where the climate and fauna shift from tropic to temperate. Despite its biogeographic importance, the marine biodiversity of this area is currently poorly studied (e.g., Nakae et al. 2018). With regard to the zooxanthellate corals, no specimen-based distributional records have been made since Yabe and Sugiyama's pioneering study in this area (e.g., Yabe et al. 1936; Yabe and Sugiyama 1941). Additionally, the major known habitats of the three euphylliid corals currently reported, such as turbid, sheltered, and mesophotic zones, have tended to be outside the research interests of coral surveys. One of the unique features of the geography of Amami-Oshima island is its many bays with a great depth range $(<30 \mathrm{~m})$ originating from the Rias Coast. This might have caused coral assemblages to remain that are dominated by zooxanthellate corals, which are tolerant to low light intensity, such as those belonging to the genus Leptoseris (Fujii et al. 2018). Although it remains to be verified that the observed habitat and the morphological features of F. paraancora in this study were comparatively different from the other two species (Veron 2000), the three euphylliid corals reported in the present study were found in comparatively sheltered environments. Further examination focused on turbid, sheltered environments or on the upper mesophotic zones will help us to more thoroughly understand the diversity and distributional patterns of not only the three euphylliid corals but also other zooxanthellate corals, such as mushroom corals occurring on sandy habitats (e.g., Gittenberger et al. 2015; Waheed et al. 2015b; Hoeksema and Suharsono 2019).

\section{Acknowledgments}

We thank the following for providing the precious specimens and their support for the sampling: Shin Nishihira, Chihiro Watanabe, Masaru Mizuyama (Diving Team Snuck Snufkin), and James Davis Reimer (University of the Ryukyus) at Okinawajima island; Sadao Yokoyama (Setouchi Marine Biological Institute) at Amami-Oshima island; and the Japanese Society for Coral Taxonomy at Amami-Oshima island and Miyako Islands. We also thank Allen G. Collins and Allison Becker (Smithsonian National Museum of Natural History) for providing information on the deposited specimens in USNM. We also thank for the two anonymous reviewers for their suggestions and comments to improve this report. The sample collections were conducted with the agreement from Setouchi fishery association and both Kagoshima and Okinawa prefectures.

This study was partially supported by JSPS KAKENHI Grant Numbers 17K15198 and 17H01913 and the "Establishment of Research and Education Network on Biodiversity and Its Conservation in the Satsunan Islands" project of Kagoshima University adopted by the Ministry of Education, Culture, Sports, Science and Technology, Japan.

\section{References}

Alloiteau, J. 1952. Madréporaires post-paléozoiques. Pp. 539-684, pls 1-10. In: Piveteau, J. (Ed.) Traité de Paléontologie. Masson, Paris.

Benzoni, F., Arrigoni, R., Waheed, Z., Stefani, F., and Hoeksema, B. W. 2014. Phylogenetic relationships and revision of the genus Blastomussa (Cnidaria: Anthozoa: Scleractinia) with description of a new species. Raffles Bulletin of Zoology 62: 358-378.

Best, M. B., Hoeksema, B.W., Moka, W., Moll, H., and Suharsono, S. I. N. 1989. Recent scleractinian coral species collected during the Snellius-II Expedition in eastern Indonesia. Netherlands Journal of Sea Research 23: 107-115.

Cairns, S. D. 1999. Species richness of recent Scleractinia. Atoll Research Bulletin 459: 1-46.

Diving Team Snuck Snufkin. 2015. Life of Oura Bay, Nanpou Shinsya, Kagoshima, 123 pp. [In Japanese]

Eguchi, M. 1973. On some new or little known corals from Japan and Australia. Publications of the Seto Marine Biological Laboratory 20: 81-87.

Eguchi, M. and Miyawaki,T. 1975. Systematic study of the scleractinian corals of Kushimoto and its vicinity. Bulletin of Marine Parks Research Station 1: 47-62.

Eyal, G., Eyal-Shaham, L., Cohen, I., Tamir, R., Ben-Zvi, O., Sinniger, F., and Loya, Y. 2016. Euphyllia paradivisa, a successful mesophotic coral in the northern Gulf of Eilat/Aqaba, Red Sea. Coral Reefs 35: 91-102.

Fujii, T., Tachikawa, H., and Yokochi, H. 2018. First record of the coral Leptoseris amitoriensis (Scleractinia, Agariciidae) from Amamioshima Island, Japan. TAXA, Proceedings of the Japanese Society of Systematic Zoology 44: 52-57. [In Japanese with English abstract]

Gittenberger, A., Draisma, S., Arbi, U., Langenberg, V., Erftemeijer, P., Tuti, Y., and Hoeksema, B.W. 2015. Coral reef organisms as bioregion indicators off Halmahera, Moluccas, Indonesia. Aquatic Conservation: Marine and Freshwater Ecosystems 25: 743-755. 
Hoeksema, B. W. and Waheed, Z. 2012. It pays to have a big mouth: mushroom corals ingesting salps at northwest Borneo. Marine Biodiversity 42: 297-302.

Hoeksema, B.W. and Suharsono, G. 2019. The role of maximum shelf depth versus distance from shore in explaining a diversity gradient of mushroom corals (Fungiidae) off Jakarta. Diversity 11: 46.

Hsieh, H., Wei, N., Lu, Y. L., Jeng, M. S., Tsai, W. S., and Chen, C. 2001. Unexpectedly high coral coverage in Chinwan Inner Bay, Pescadores: a proposed site for a Marine Protection Area. Coral Reefs 20: $316-317$.

International Union for Conservation of Nature. 2019. Catalaphyllia jardinei. In: The IUCN red list of threatened species. Version 2019-1. Available at https:/www.iucnredlist.org/species/ 132890/3479919 (02 July 2019).

Kenyon, J., Maragos, J., and Fenner, D. 2011. The occurrence of coral species reported as threatened in federally protected waters of the US Pacific. Journal of Marine Biology 2011: 1-12.

Kushimoto Marine Park Center. 1977. Kushimoto san ishi Sango rui [Scleractinian Corals from Kushimoto]. Kushimoto Marine Park Center, Kushimoto, 55 pp. [In Japanese]

Luzon, K. S., Lin, M. F., Lagman, M. C. A. A., Licuanan, W. R. Y., and Chen, C. A. 2018. Correction: Resurrecting a subgenus to genus: molecular phylogeny of Euphyllia and Fimbriaphyllia (order Scleractinia; family Euphylliidae; clade V). PeerJ 6: e4074/correction-1.

Ministry of Environment, Japan. 2017. Red list keisai sango no syu goto no kankyou tokusei ni tuite [Environmental characteristics of the coral species in the red list of marine organisms 2017]. Available at https://www.env.go.jp/nature/kisho/sango_tokusei01.pdf (02 July 2019). [In Japanese]

Miyakojima City Board of Education. 2016. [Chapter 2 Characteristic and present situation]. Pp. 13-38. In: Miyakojima City Board of Education (Ed.) Kuni shitei meikatsu oyobi tennen kinenbutsu "Yabiji" hozon katsuyou keikaku sakutei houkokusho [Reports for Formulation of Conservation and Practical Plan for the Scenic Spot and Natural Monument Designated by the Japanese Government "Yabiji"]. Miyakojima City Board of Education, Miyakojima. [In Japanese]

Montgomery, A, D., Fenner, D., and Toonen, R. J. 2019. Annotated checklist for stony corals of American Sāmoa with reference to mesophotic depth records. ZooKeys 849: 1-170.

Nakae, M., Motomura, H., Hagiwara, K., Senou, H., Koeda, K., Yoshida, T., Tashiro, S., Jeong, B., Hata, H., Fukui, Y., Fujiwara, K., Yamakawa, T., Aizawa, M., Shinohara, G., and Matsuura, K. 2018. An annotated checklist of fishes of Amami-oshima Island, the Ryukyu Islands, Japan. Memoirs of National Museum of Natural Science, Tokyo 52: 205-361.

Nishihira, M. and Veron, J. E. N. 1995. Nihon no zoushou sango rui [Hermatypic Corals of Japan]. Kaiyusha, Tokyo, 392 pp. [In Japanese]

Nomura, K. and Hirabayashi, I. 2018. Mass mortality of coral communities caused by abnormality low water temperature observed at Kii peninsula west coast for winter season in 2018. Marine Pavilion Supplement No. 7: 1-14. [In Japanese]

Nomura, K. and Mezaki, T. 2015. Reef building corals from Otsuki, Kochi prefecture, Japan. Kuroshio Biosphere 2: 29-41. [In Japanese with English abstract]

Randall, R. H. and Myers, R. F. 1983. Guide to the Coastal Resources of Guam: Vol. 2, The Corals. University of Guam Press, Mangilao, $128 \mathrm{pp}$.

Randall, R. H. 2003. An annotated checklist of hydrozoan and scleractinian corals collected from Guam and other Mariana Islands. Micronesica 35-36: 121-137.
Saville-Kent, W. 1893. The Great Barrier Reef of Australia; its Products and Potentialities. W. H. Allen \& Co., London, xix +387 pp., 1-48 pls, 1-16 chromo pls.

Shirai, S. 1977. Ecological Encyclopedia of Marine Animals of the Ryukyu Islands in Color. Shinsei-Tosho, Naha, 636 pp. [In Japanese]

Sinniger, F., Harii, S., Humblet, M., Nakamura, Y., Ohba, H., and Prasetia, R. 2019. Ryukyu Islands, Japan. Pp. 213-248. In: Loya, Y., Puglise, K., and Bridge, T. (Eds) Mesophotic Coral Ecosystems. Coral Reefs of the World, Vol. 12. Springer International Publishing, Bazel.

Turak, E., Devantier, L., and Erdmann, M. 2012. Euphyllia baliensis sp. nov. (Cnidaria: Anthozoa: Scleractinia: Euphylliidae): a new species of reef coral from Indonesia. Zootaxa 3422: 52-61.

Veron, J. E. N. 1990. New Scleractinia from Japan and other Indo-West Pacific countries. Galaxea 9: 95-173.

Veron, J. E. N. 1992. Hermatypic corals of Japan. Australian Institute of Marine Science Monograph Series Volume 9. Australian Institute of Marine Science, Townsville, 234 pp.

Veron, J. E. N. 2000. Genus Catalaphyllia. Pp. 82-83. In: Veron, J. E. N. (Ed.) Corals of the World Volume 2. Australian Institute of Marine Science, Townsville.

Veron, J. E. N. and Pichon, M. 1980. Scleractinia of eastern Australia. Part III. Families Agariciidae, Siderastreidae, Fungiidae, Oculinidae, Merulinidae, Mussidae, Pectiniidae, Caryophylliidae, Dendrophylliidae Volume 4. Australian Institute of Marine Science, Townsville, 422 pp.

Waheed, Z. and Hoeksema, B.W. 2014. Diversity patterns of scleractinian corals at Kota Kinabalu, Malaysia, in relation to depth and exposure. Raffles Bulletin of Zoology 62: 66-82.

Waheed, Z., Benzoni, F., van der Meij, S. E. T., Terraneo, T. I., and Hoeksema, B. W. 2015a. Scleractinian corals (Fungiidae, Agariciidae and Euphylliidae) of Pulau Layang-Layang, Spratly Islands, with a note on Pavona maldivensis (Gardiner, 1905). ZooKeys 517: $1-37$.

Waheed, Z., van Mil, H. G. J., Syed Hussein, M. A., Jumin, R., Golam, A. B., and Hoeksema, B.W. 2015b. Coral reefs at the northernmost tip of Borneo: an assessment of scleractinian species richness patterns and benthic reef assemblages. PLoS ONE 10: e0146006.

Wells, J. W. 1971. Notes on Indo-Pacific scleractinian corals. Part 7. Catalaphyllia, a new genus of reef corals. Pacific Science 25: 368-371.

Wolstenholme, J., Dinesen, Z. D., and Alderslade, P. 1997. Hard corals of the Darwin region, Northern Territory, Australia. Pp. 381-398. In: Hanley, J. R., Caswell, G., Megirian, D., and Larson, H.K. (Eds) Proceedings of the Sixth International Marine Biological Workshop. The Mmarine Flora and Fauna of Darwin Harbour, Northern Territory, Australia. Museums and Art Galleries of the Northern Territory and the Australian Marine Sciences Association, Darwin.

Yabe, H. and Sugiyama, T. 1941. Recent reef-building corals from Japan and the South Sea Islands under the Japanese mandate. II. The Science Reports of the Tohoku Imperial University. Second Series, Geology, Special Volum 2: 67-91.

Yabe, H., Sugiyama, T., and Eguchi, M. 1936. Recent reef-building corals from Japan and the South Sea Islands under the Japanese mandate. I. The Science Reports of the Tohoku Imperial University. Second Series, Geology, Special Volume 1: 1-66.

Yokochi, H., Shimoike, K., Kajiwara, K., Nomura, K., Kitano, Y., Matsumoto, H., Shimada, G., Sugihara, K., Suzuki, G., Tachikawa, H., Yamamoto, H., Zayasu, Y., Kimura, T., and Kohno, H. 2019. A preliminary report on hermatypic corals of Amitori Bay, Iriomotejima, Ryukyu Islands, Japan. The Study Review of Iriomote Island, 2018, 36-69. [In Japanese with English abstract] 